\title{
BioMedicine
}

\section{Comparison of pregnancy complications in unintended and intended pregnancy: A prospective follow-up study}

Follow this and additional works at: https://www.biomedicinej.com/biomedicine

Part of the Life Sciences Commons, Medical Sciences Commons, Nursing Midwifery Commons, and the Obstetrics and Gynecology Commons

c) (7)

This work is licensed under a Creative Commons Attribution 4.0 License.

\section{Recommended Citation}

Eftekhariyazdi, Mitra; Mehrbakhsh, Malihe; Neamatshahi, Mahboubeh; and Yousefi Moghadam, Manijeh (2021) "Comparison of pregnancy complications in unintended and intended pregnancy: A prospective follow-up study," BioMedicine: Vol. 11 : Iss. 4 , Article 6.

DOI: 10.37796/2211-8039.1192

This Original Articles is brought to you for free and open access by BioMedicine. It has been accepted for inclusion in BioMedicine by an authorized editor of BioMedicine. 
Comparison of pregnancy complications in unintended and intended pregnancy: A prospective follow-up study

\section{Cover Page Footnote}

We acknowledge the financial support of the deputy of research and technology, Sabzevar University of Medical Sciences, Sabzevar, Iran. 


\title{
follow-up study
}

\author{
Mitra Eftekhariyazdi ${ }^{a}$, Malihe Mehrbakhsh ${ }^{\mathrm{b}}$, \\ Mahboubeh Neamatshahi ${ }^{\mathrm{c}}$, Manijeh Yousefi Moghadam ${ }^{\mathrm{d}, *}$ \\ ${ }^{a}$ Department of Obstetrics and Gynecology, School of Medicine, Sabzevar University of Medical Sciences, Sabzevar, Iran \\ ${ }^{\mathrm{b}}$ Student Research Committee, School of Medicine, Sabzevar University of Medical Sciences, Sabzevar, Iran \\ ${ }^{c}$ Department of Community Medicine, School of Medicine, Sabzevar University of Medical Sciences, Sabzevar, Iran \\ ${ }^{\mathrm{d}}$ Department of Anesthesiology, Faculty of Medicine, Sabzevar University of Medical Sciences, Sabzevar, Iran
}

\begin{abstract}
Background and objectives: Unintended pregnancy, as a pregnancy that is mistimed, unplanned or unwanted at the time of conception, is a common experience worldwide that puts mothers at risk for mental stress and its pregnancy complications. The aim of this study was to compare three common pregnancy complications, including preeclampsia, preterm labor, and low birth weight, between unintended and intended pregnancies in Sabzevar, northeast Iran in 2019.

Materials and methods: This prospective follow-up study was conducted on 200 pregnant women (100 intended and 100 unintended pregnancies) who were between 18 and 35 years old and were referred for delivery to Shahidan Mobini Hospital, Sabzevar, Iran. Data were collected using a questionnaire and the subjects were recruited based on inclusion and exclusion criteria. Preeclampsia, preterm labor, and low birth weight were recorded after delivery and were statistically analyzed using the statistical package for social sciences (SPSS software) version 22 at the statistical significance of $<0.05$.

Results: The mean age and gravidity was significantly higher in the unintended pregnancy group compared to intended pregnancy group. The most common complication overall was low birth weight $(25 \%$ of unintended and $16 \%$ of the intended pregnancies) followed by preterm labor (12\% of unintended and $11 \%$ of intended pregnancies) and preeclampsia (5\% of unintended and $1 \%$ of intended pregnancies). No significant relationship was found between the time of delivery and type of pregnancy $(P=0.50)$.

Conclusion: The findings of this study indicated that unintended pregnancy can be a risk factor for pregnancy complications including preeclampsia and low birth weight and that sophisticated monitoring should be performed for better management of these complications.
\end{abstract}

Keywords: Low birth weight, Preeclampsia, Preterm labor, Unintended pregnancy

\section{Introduction}

A $\mathrm{s}$ the parents increasingly decide to have smaller families, they are more trying to control the timing and number of their births [1-5]. While contraceptive methods are not hundred percent successful in preventing pregnancies, unintended pregnancy is always likely to occur. Whether the unintended pregnancy is because of failed contraceptive method or other reasons, managing the pregnancy will be the most important issue [1, 6-11]. Unintended pregnancies are defined as pregnancies that are unwanted, unplanned or mistimed at the time of conception [12]. According to the latest report about the rate of unintended pregnancy, this issue is still substantially high in developing regions in comparison to developed countries [13-15]. In a recent metaanalysis, the global prevalence of unintended pregnancy has been reported as $48 \%$, with higher prevalence in low-income countries and regions such as Sub-Saharan Africa, West Asia, North Africa and Central and South Asia [16]. In Iran, the prevalence of unintended pregnancy has been reported to be about $30 \%$ [17-19].

Received 9 January 2021; revised 18 February 2021; accepted 1 March 2021.

Available online 1 December 2021.

* Corresponding author at: School of Medicine, Heshmatie Hospital, Sabzevar University of Medical Sciences, Sabzevar, Iran.

E-mail address: drmanijehyousefi@yahoo.com (M. Yousefi Moghadam). 
Reproductive health services are mandatory for these women in order to ensure the health of both mother and child [1]. It has been reported that unintended pregnancies will result in adverse health outcomes for women, their families, and society [20]. Women with unintended pregnancies are more vulnerable to developing suicidal ideation, depression and poor nutrition during pregnancy. They may also experience more physical and psychological violence, unstable family relationships and risk of miscarriage and having low birth weight infants $[12,20]$. Some mothers may think of abortion, which is mostly an unsafe induced abortion. Approximately $13 \%$ of maternal death is because of such complicated abortions [21-24]. Also, women with unintended pregnancies are more likely to start their pregnancy care late and deny their pregnancy. Such behaviors will increase the risk of developing various pregnancy complications [20, 25-28].

Controversial findings have been reported regarding the possible adverse effects of unintended pregnancy in different countries. Preeclampsia, low birth weight (LBW) and preterm labor are the three most commonly reported complications of unintended pregnancies [29-33]. Considering the importance of the negative consequence of unintended pregnancy and conflicting results, further studies are required to evaluate the relationship between pregnancy intention and potential negative outcomes [34].

Evaluation of these complications in every region by health system managers, policy makers and clinicians, allowing for tailor-made solutions according to the women's local condition and needs to reduce the risk of such possible complications. The aim of this study was to evaluate the three most common pregnancy complications, including preeclampsia, preterm labor and LBW in women with intended and unintended pregnancies in Sabzevar, northeast Iran in 2019.

\section{Methods}

This prospective follow-up study was conducted in Shahidan Mobini Hospital, Sabzevar, Iran. From December 2018 to September 2019, every married pregnant woman who was referred for prenatal care to the obstetrics-gynecology clinic of hospital was considered to enroll in this study. In order to reduce the possible effect of maternal age on LBW, preterm labor and preeclampsia on the study population, only pregnant women who were between the age of 18 and 35 years old were included in the study [35]. The exclusion criteria were past history of gestational hypertension, gestational diabetes mellitus, fetal malformations, preterm birth, preeclampsia or diagnosis of twin pregnancy. A total of 200 pregnant women, who meet the inclusion criteria, were selected using convenient sampling.

After getting informed consent, in the first visit of women to the clinic a researcher-made questionnaire which included demographic and clinical characteristics of mothers such as age, educational level, gravida, gestational age (weeks) and pregnancy occurrence status (wanted or unwanted from the perspective of both parents) were completed by each of them.

The women were grouped into two groups of unintended or intended pregnancy, according to their response to related questions ( 100 women in each group). During pre- and postnatal care followup visits, all women were regularly and closely assessed in terms of occurrence of three most common pregnancy complications, including preeclampsia, preterm labor and LBW by a maternalfetal medicine fellowship. All information were recorded.

\subsection{Theoretical/operational definition}

The infant's birth weight lower than 2500 grams and greater than 1500 grams, regardless of gestational age, were considered as LBW [36]. Preterm labor was considered when the fetus was born before the 37th weeks of gestation [37]. Preeclampsia was considered when the maternal systolic and diastolic blood pressure was higher than $140 \mathrm{mmHg}$ and $90 \mathrm{mmHg}$ respectively, besides presence of proteinuria [38].

\subsection{Sample size calculation}

Estimation of sample size was based on $43 \%$ prevalence of unintended pregnancy and its risk factors in previous study [39]. At a level of $\alpha=.05$ with a power of 0.8 , we calculated that it was necessary to enroll 180 eligible women for this study, so in order to allow for a withdrawal rate of $10 \%$, we planned to recruit 200 women (100 women with unintended pregnancies and 100 with intended pregnancies).

\subsection{Ethical consideration}

The protocol of the study was approved by the ethics committee of the Sabzevar University of Medical Sciences, Sabzevar, Iran. The researchers explained the objectives of the study to the participants, and informed consent was obtained from all of them. The participants were informed of their 
right to refuse or decline participation in the study, at any time and for any reason. They were thoroughly informed and assured that refusing to participate in the study will not affect their current or future medical care.

\subsection{Statistical analysis}

Continuous data were assessed for normality using the Kolmogorov-Smirnov test. Continuous data were presented using mean and standard deviation (SD) while the categorical data were presented using frequency and percentage. Continuous variables were compared between groups using the independent t-test while the categorical variables were compared between groups using the chisquare or Fisher exact test. Associations between maternal pregnancy intention and occurrence of three most common pregnancy complications, including preeclampsia, preterm labor and LBW, were estimated using logistic regression procedures. We estimated the ORs to assess the strength of the associations adjusted for potential confounders and used the $95 \%$ CIs to test significance. Data analysis was performed using the statistical package for social sciences (SPSS) software (IBM Inc, Chicago, Il, USA) version 22.0. Level of statistical significance was considered as 0.05 .

\section{Results}

Among the study participants, the mean age of women with unintended and intended pregnancy was $29.29 \pm 5.01$ and $26.89 \pm 4.54$ years respectively. Demographic characteristics of the pregnant mothers in the study groups are presented in Table 1. Women in the unintended pregnancy group were significantly older $(\mathrm{p}<0.001)$ and had more pregnancies $(\mathrm{p}<0.001)$ (Table 1$)$.

Overall, the most common pregnancy complication was LBW $(20.5 \%)$ followed by preterm labor $(11.5 \%)$ and preeclampsia $(3 \%)$. The prevalence of pregnancy complications among study groups is presented in Table 2. Although the prevalence of three assessed pregnancy complications was higher in the unintended pregnancy group, there was no statistically significant difference in terms of these complications between intended and unintended pregnancy groups (Table 2).

Table 3 shows the results of logistic regression analyses and revealed the relationship between maternal pregnancy intention and the pregnancy complications (preeclampsia, LBW and preterm labor). Women who reported their pregnancies as unintended were 2.11 times more likely to have a baby with LBW than women with intended pregnancies. Also, women with unintended pregnancy was at increased odds of experiencing preterm labor or preeclampsia, even after adjusting for maternal age and gravida.

\section{Discussion}

The present study evaluated the prevalence of three common pregnancy complications among women with intended and unintended pregnancy in Iran. Although the prevalence of these pregnancy complications was higher among the unintended pregnant mothers compared to intended pregnancy group, the difference was not statistically significant. Relative small sample size is a possible explanation for these seemingly contradictory results. However, the results of regression models showed that women with unintended pregnancies were more than twice as likely to have a child with LBW, even after adjusting for maternal age and gravida. The result of recently published study in Bangladesh also revealed that women with unintended pregnancies had three times more likely to have LBW babies [40]. Also, the results of two cohort studies in Iran revealed that there was a significant relationship between unwanted pregnancy and LBW [4142]. These findings are generally consistent with the results of our study.

Maternal age is one of the most common and important factors in predicting unintended pregnancy. Usually, unintended pregnancies are more prevalent among women who are at the younger and older ends of the childbearing age range. On the other hand, these women are more likely to have LBW infants [43-46]. In line with this, the results of our study revealed that women with unintended

Table 1. Demographic and clinical characteristics of all pregnant women.

\begin{tabular}{lllll}
\hline Variables & & Unintended pregnancy $(\mathrm{n}=100)$ & Intended pregnancy $(\mathrm{n}=100)$ & $\mathrm{P}$-value \\
\hline Education level & Primary & $79(79 \%)$ & $69(69 \%)$ & 0.10 \\
& Secondary & $21(21 \%)$ & $31(31 \%)$ & $<0.001^{\mathrm{a}}$ \\
Age (years) & $29.29 \pm 5.01$ & $26.89 \pm 4.54$ & $<0.001^{\mathrm{a}}$ \\
Gravida & & $1.68 \pm 0.86$ & 0.50 \\
Gestational age at delivery (weeks) & $38.97 \pm 1.4$ & $39.15 \pm 17.1$ & \\
\hline
\end{tabular}

\footnotetext{
${ }^{a}$ Significant at $\alpha=0.01$.
} 
Table 2. Comparison of pregnancy complication in women with intended and unintended pregnancy.

\begin{tabular}{|c|c|c|c|c|c|c|}
\hline \multirow[t]{2}{*}{ Complications } & \multicolumn{2}{|c|}{ Unintended pregnancy $(\mathrm{n}=100)$} & \multicolumn{2}{|c|}{ Intended pregnancy $(\mathrm{n}=100)$} & \multirow[t]{2}{*}{ Total } & \multirow[t]{2}{*}{ P-value $x$} \\
\hline & Yes & No & Yes & No & & \\
\hline Preeclampsia & $5(5 \%)$ & $95(95 \%)$ & $1(1 \%)$ & $99(99 \%)$ & $6(3 \%)$ & 0.21 \\
\hline LBW & $25(25 \%)$ & $75(75 \%)$ & $16(16 \%)$ & $84(84 \%)$ & $41(20.5 \%)$ & 0.16 \\
\hline Preterm labor & $12(12 \%)$ & $88(88 \%)$ & $11(11 \%)$ & $89(89 \%)$ & $23(11.5 \%)$ & 0.50 \\
\hline
\end{tabular}

LBW = Low Birth Weight; $x$ Fisher exact test was used for the analysis.

Table 3. Association between maternal pregnancy intention and pregnancy complications ${ }^{a}$.

\begin{tabular}{lllll}
\hline Variables & Crude OR & $95 \%$ CI & Adjusted OR $^{\mathrm{b}}$ & 95\% CI \\
\hline Preeclampsia & 1.71 & $0.95-3.64$ & 1.18 & $0.67-2.31$ \\
LBW & 2.53 & $0.8-4.51$ & 2.11 & $0.54-3.35$ \\
Preterm labor & 1.36 & $0.63-1.47$ & 1.06 & $0.53-1.69$ \\
\hline
\end{tabular}

OR, Odds ratio; CI, Confidence interval.

a Reference group is women with intended pregnancies.

b All outcomes adjusted for mothers' age and gravida.

pregnancies were significantly older age than women with intended pregnancies.

According to the results of our study, preeclampsia was more prevalent in women with unintended pregnancy, compared to those with intended pregnancy. The results of a study by Adu-Bonsaffoh et al. in Ghana revealed that preeclampsia is more prevalent in unintended pregnancies [29]. Also, the results of another study in India showed that unintended pregnancy is associated with significantly increased risk of preeclampsia and postpartum preeclampsia [47]. It has been previously indicated that advanced maternal age is associated with increased risk and severity of preeclampsia in pregnant women [48-50]. In addition, multiple gestation has been reported as another risk factor for preeclampsia [51-52]. In this study, women with unintended pregnancies were older and had had higher gravidity. After adjusting for these factors, the relationship between unintended pregnancy and preeclampsia was attenuated, but still elevated.

A recent study in Iran indicated that neither preeclampsia nor LBW and preterm labor were related to unintended pregnancy and reported the higher rate of cesarean section and inappropriate weight gain during pregnancy, as the possible outcomes of unintended pregnancy [30]. Unfortunately, evaluating these two factors was beyond the aims of this study, which focused on the three most common pregnancy complications between unintended and intended pregnancy.

The prospective nature of this study and regular follow-up of the women are strengths of the study, however, using larger number of participants would be useful to draw a more concrete conclusion about the results. Lack of information regarding women's pre-conception, antenatal, delivery and postnatal behaviors, as potential confounders, is another limitation that could be considered in further studies.

\section{Conclusion}

In conclusion, the findings of this study indicated that unintended pregnancy can be a risk factor for pregnancy complications including preeclampsia and LBW. Therefore, tailor-made interventions are required to be developed and implemented for reducing unintended pregnancies and prevent their potential common complications.

\section{Acknowledgments}

We acknowledge the financial support of the deputy of research and technology, Sabzevar University of Medical Sciences, Sabzevar, Iran (Grant number: 96008).

\section{Conflict of interest}

The authors declared no potential conflicts of interest with respect to the research, authorship, and/ or publication of this article.

\section{References}

[1] Bearak J, Popinchalk A, Alkema L, Sedgh G. Global, regional, and subregional trends in unintended pregnancy and its outcomes from 1990 to 2014: estimates from a Bayesian hierarchical model. Lancet Glob Health 2018;6(4):e380-9.

[2] Erfani A, Hosseini H, Nojomi M. Unintended pregnancies in Hamedan, Iran: Levels and determinants. Women Health 2019;59(3):318-33.

[3] Gholipour Baradari A, Firouzian A, Hasanzadeh Kiabi F, Emami Zeydi A, Khademloo M, Nazari Z, et al. Bolus administration of intravenous lidocaine reduces pain after an elective caesarean section: Findings from a randomised, double-blind, placebo-controlled trial. J Obstet Gynaecol 2017;37(5):566-70.

[4] Aztlan-James EA, McLemore M, Taylor D. Multiple Unintended Pregnancies in U.S. Women: A Systematic Review. Womens Health Iss 2017;27(4):407-13.

[5] Huynh ST, Yokomichi H, Akiyama Y, Kojima R, Horiuchi S, Ooka T, et al. Prevalence of and factors associated with unplanned pregnancy among women in Koshu, Japan: crosssectional evidence from Project Koshu, 2011-2016. BMC Preg Childbirth 2020;20(1):397. 
[6] Beyene GA. Prevalence of unintended pregnancy and associated factors among pregnant mothers in Jimma town, southwest Ethiopia: a cross sectional study. Contracept Reprod Med 2019;4:8.

[7] Finer LB, Zolna MR. Shifts in intended and unintended pregnancies in the United States, 2001-2008. Am J Public Health 2014;104(Suppl 1):S43-8.

[8] Finer LB, Zolna MR. Declines in unintended pregnancy in the United States, 2008-2011. N Engl J Med 2016;374(9): 843-52.

[9] Grindlay K, Dako-Gyeke P, Ngo TD, Eva G, Gobah L, Reiger ST, et al. Contraceptive use and unintended pregnancy among young women and men in Accra, Ghana. PLoS One 2018;13(8):e0201663.

[10] Ganle JK, Amoako D, Baatiema L, Ibrahim M. Risky sexual behaviour and contraceptive use in contexts of displacement: insights from a cross-sectional survey of female adolescent refugees in Ghana. Int J Equity Health 2019;18(1):127.

[11] Kallner HK, Danielsson KG. Prevention of unintended pregnancy and use of contraception-important factors for preconception care. Ups J Med Sci 2016;121(4):252-5.

[12] Yazdkhasti M, Pourreza A, Pirak A, Abdi F. Unintended Pregnancy and Its Adverse Social and Economic Consequences on Health System: A Narrative Review Article. Iran J Public Health 2015;44(1):12-21.

[13] Tapales A, Finer L. Unintended pregnancy and the changing demography of American women, 1987-2008. Demogr Res 2015;33:1257-70.

[14] Habib MA, Raynes-Greenow C, Nausheen S, Soofi SB, Sajid M, Bhutta ZA, et al. Prevalence and determinants of unintended pregnancies amongst women attending antenatal clinics in Pakistan. BMC Preg Childbirth 2017;17(1):156.

[15] Troutman M, Rafique S, Plowden TC. Are higher unintended pregnancy rates among minorities a result of disparate access to contraception? Contracept Reprod Med 2020;5:16.

[16] Bearak J, Popinchalk A, Ganatra B, Moller AB, Tunçalp Ö, Beavin $C$, et al. Unintended pregnancy and abortion by income, region, and the legal status of abortion: estimates from a comprehensive model for 1990-2019. Lancet Glob Health 2020;8(9):e1152-61.

[17] Moosazadeh M, Nekoei-Moghadam M, Emrani Z, Amiresmaili M. Prevalence of unwanted pregnancy in Iran: a systematic review and meta-analysis. Int $\mathrm{J}$ Health Plann Manage 2014;29(3):e277-90.

[18] Asadi Sarvestani K, Ahmadi A, Enayat H, Movahed M. Level and Factors Related to Unintended Pregnancy with a Brief Review of New Population Policies in Iran. Iran J Public Health 2017;46(7):973-81.

[19] Sayehmiri K, Ebtekar F, Zarei M, Gheshlagh RG. Prevalence of unwanted pregnancy among Iranian women: an updated meta-analysis. BMC Preg Childbirth 2019;19(1):491.

[20] Hajizadeh M, Nghiem S. Does unwanted pregnancy lead to adverse health and healthcare utilization for mother and child? Evidence from low- and middle-income countries. Int J Public Health 2020;65(4):457-68.

[21] Shah I, Ahman E. Unsafe abortion: global and regional incidence, trends, consequences, and challenges. J Obstet Gynaecol Can 2009;31(12):1149-58.

[22] Tsegaye AT, Mengistu M, Shimeka A. Prevalence of unintended pregnancy and associated factors among married women in west Belessa Woreda, Northwest Ethiopia, 2016. Reprod Health 2018;15(1):201.

[23] Kantorová V. Unintended pregnancy and abortion: what does it tell us about reproductive health and autonomy? Lancet Glob Health 2020;8(9):e1106-7.

[24] Steinberg JR, Rubin LR. Psychological Aspects of Contraception, Unintended Pregnancy, and Abortion. Policy Insights Behav Brain Sci 2014;1(1):239-47.

[25] Godfrey EM, Zapata LB, Cox CM, Curtis KM, Marchbanks PA. Unintended pregnancy risk and contraceptive use among women 45-50 years old: Massachusetts, 2006, 2008, and 2010. Am J Obstet Gynecol 2016;214(6):712.e1-8.
[26] Johnson-Mallard V, Kostas-Polston EA, Woods NF, Simmonds KE, Alexander IM, Taylor D. Unintended pregnancy: a framework for prevention and options for midlife women in the US. Womens Midlife Health 2017;3:8.

[27] Harlow SD, Dusendang JR, Hood MM, Woods NF. Contraceptive preferences and unmet need for contraception in midlife women: where are the data? Womens Midlife Health 2017;3:6

[28] Van Heertum K, Liu J. Contraception and conception in Midlife: a review of the current literature. Womens Midlife Health 2017;3:3.

[29] Adu-Bonsaffoh K, Seffah JD. Linking unintended pregnancy to the burden of pre-eclampsia in a tertiary hospital in Ghana. J West Afr Coll Surg 2015;5(4):17-29.

[30] Omani-Samani R, Ranjbaran M, Mohammadi M, Esmailzadeh A, Sepidarkish M, Maroufizadeh S, et al. Impact of Unintended Pregnancy on Maternal and Neonatal Outcomes. J Obstet Gynaecol India 2019;69(2):136-41.

[31] Shah PS, Balkhair T, Ohlsson A, Beyene J, Scott F, Frick C. Intention to become pregnant and low birth weight and preterm birth: a systematic review. Matern Child Health J 2011;15(2):205-16.

[32] Hussain R. Abortion and unintended pregnancy in Kenya. Issues Brief (Alan Guttmacher Inst) 2012 May;(2):1-4.

[33] Ranatunga IDJC, Jayaratne K. Proportion of unplanned pregnancies, their determinants and health outcomes of women delivering at a teaching hospital in Sri Lanka. BMC Preg Childbirth 2020 Nov 5;20(1):667.

[34] Hall JA, Benton L, Copas A, Stephenson J. Pregnancy Intention and Pregnancy Outcome: Systematic Review and Meta-Analysis. Matern Child Health J 2017;21(3):670-704.

[35] Omane-Adjepong M, Oduro FT, Annin K. A multinomial regression analysis of unplanned pregnancies in Ahafo Ano South District, Ghana. Am Int J Contemp Res 2012;2(12): $90-7$.

[36] Cutland CL, Lackritz EM, Mallett-Moore T, Bardají A Chandrasekaran R, Lahariya C, et al. Low Birth Weight Working Group. Low birth weight: Case definition \& guidelines for data collection, analysis, and presentation of maternal immunization safety data. Vaccine 2017;35(48 Pt A): 6492-500.

[37] Haram K, Mortensen JH, Wollen AL. Preterm delivery: an overview. Acta Obstet Gynecol Scand 2003;82(8):687-704.

[38] Rana S, Lemoine E, Granger JP, Karumanchi SA. Preeclampsia: Pathophysiology, Challenges, and Perspectives. Circ Res 2019;124(7):1094-112.

[39] Palamuleni ME, Adebowale AS. Prevalence and determinants of unintended pregnancies in Malawi. Afr Pop Stud 2014;28(1):551-63.

[40] Rahman M, Nasrin SO, Rahman M, Rahman A, Mostofa G, Jesmin SS, et al. Maternal pregnancy intention and its association with low birthweight and pregnancy complications in Bangladesh: findings from a hospital-based study. Int Health 2019;11(6):447-54.

[41] Hosseini M, Ghavami B, Salimzadeh H, Eftekhar Ardabili H. Low birth weight and its relation to unwanted pregnancies A cohort study. J Sch Public Health Inst Public Health Res 2009; 7(1):11-8.

[42] Parhizkar A, Sahsavari S. Comparison of infants' growth indicators in wanted and unwanted pregnancy at health centers of Sanandaj in 2014-2015. Iran J Obstet Gynecol Infertil 2016;19(11):24-30.

[43] Aziz Ali S, Aziz Ali S, Khuwaja N. Determinants of Unintended Pregnancy among Women of Reproductive Age in Developing Countries: A Narrative Review. J Midwifery Reproduct Health 2016;4(1):513-21.

[44] Dennis JA, Mollborn S. Young maternal age and low birth weight risk: An exploration of racial/ethnic disparities in the birth outcomes of mothers in the United States. Soc Sci J 2013;50(4):625-34.

[45] Aras RY. Is maternal age risk factor for low birth weight? Arch Med Health Sci 2013;1:33-7. 
[46] Oulman E, Kim TH, Yunis K, Tamim H. Prevalence and predictors of unintended pregnancy among women: an analysis of the Canadian Maternity Experiences Survey. BMC Preg Childbirth 2015;15:260.

[47] Dehingia N, Dixit A, Atmavilas Y, Chandurkar D, Singh K, Silverman J, et al. Unintended pregnancy and maternal health complications: cross-sectional analysis of data from rural Uttar Pradesh, India. BMC Preg Childbirth 2020;20(1):188.

[48] Das S, Das R, Bajracharya R, Baral G, Jabegu B, Jø Odland, et al. Incidence and risk factors of pre-eclampsia in the paropakar maternity and women's hospital, Nepal: A retrospective study. Int J Environ Res Public Health 2019;16(19):3571.

[49] Khalil A, Syngelaki A, Maiz N, Zinevich Y, Nicolaides KH. Maternal age and adverse pregnancy outcome: a cohort study. Ultrasound Obstet Gynecol 2013;42(6):634-43.
[50] Lamminpää R, Vehviläinen-Julkunen $K$, Gissler $M$, Heinonen S. Preeclampsia complicated by advanced maternal age: a registry-based study on primiparous women in Finland 1997-2008. BMC Preg Childbirth 2012;12:47.

[51] Andarge RB, Anshebo AA, Halil HM, Kebede BA, Abdo RA. Prevalence and Associated Factors of Pre-eclampsia among Pregnant Women at Antenatal Booking in the Halaba Kullito General Hospital, Southern Ethiopia. J Women's Health Care 2020;9:496.

[52] Belay AS, Wudad T. Prevalence and associated factors of pre-eclampsia among pregnant women attending anti-natal care at Mettu Karl referal hospital, Ethiopia: cross-sectional study. Clin Hypertens 2019;25:14. 